\title{
Surface Modified Electrode Used In the Electro-Analysis of N- Acetyl P-Aminophenol- A Pharmaceutical Drug
}

\author{
Duke Orata $^{* 1}$, Amir Yusuf ${ }^{* 1}$ and Nineza Claire ${ }^{2}$,Marina Mukabi ${ }^{1}$, Damaris \\ Mbui $^{1}$ \\ ${ }^{1-}$ Department of Chemistry University of Nairobi Box 30197-00100, Nairobi \\ 2- University of Burundi Bujumbura, Burundi.
}

\begin{abstract}
In this paper we report on the electrochemical behavior of paracetamol or N-acetyl-p-aminophenol. In the electro-analysis bare carbon graphite and bentonite modified working electrode has been used in conjunction with cyclic voltammetry to study its redox properties. The results indicate that, the oxidation and reduction potentials of paracetamol occur at $0.600 \mathrm{~V}$ and $0.750 \mathrm{~V}$. The paracetamol cyclic voltammogram is reversible.From the results obtained we observe that, paracetamol interacts with consumables such tea and milk; metal ions such as $\mathrm{CO}^{2+}$ and $\mathrm{Fe}^{2+}$. It is also shown to interact with vitamin, ferrous fumarate and hydrocortisone. The observed electrochemical behaviour of paracetamol, if replicated at the cellular level, can give insight into its mechanistic and interactive pathways.
\end{abstract}

Keywords: $N$-acetyl-p-aminophenol (paracetamol), surface modified electrode, working electrode

\section{Introduction}

Paracetamol or N-acetyl-p-aminophenol is an analgesic which is capable of relieving pain (headache reliever) and fever (1). The dose level is about $1000 \mathrm{mg}$ per given time but not exceeding a daily dose of 4000 $\mathrm{mg}$. An overdose taken for some time can be fatal since it slowly damages the liver $(2,3$ and 4$)$. As compared to other analgesics, paracetamol has little anti-inflammatory activity.

The mechanism of action is thought to be inhibition of cyclo-oxygenase (5). It acts through three pathways $(6,7$,and 8$)$. One of the methods used to synthesize paracetamol is by nitrating phenol to give a mixture of 2-nitrophenol and 4-nitrophenol. The latter is then reduced with sodium borohydride to give 4aminophenol. This is then acetylated using acetic anhydride to give the product (9). In place of borohydride, hydrogenation is also a good alternative $(10,11)$. The synthesis is shown in Scheme 1.

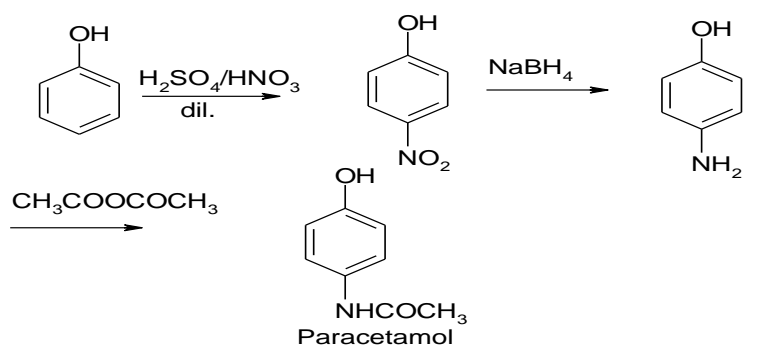

Scheme 1: Synthesis of paracetamol

In this paper we report on the redox behavior of paracetamol, using a bare carbon graphite working electrode and a clay montmorillonite (bentonite) modified electrode.

The results suggest that paracetamol has redox active moieties/functional groups. This is exemplified by the reversible cyclic voltammograms obtained. In this paper we also report its interaction with consumables Vitamin C, tea and milk, metal ions and prescription drugs such as ferrous fumarate and hydrocortisone.

\section{Experimental section:}

All the prescription drugs-paracetamol, ferrous fumarate, hydrocortisone and vitamin $\mathrm{C}$ were purchased from reputable pharmaceutical drug stores in Nairobi. They were used as received without further purification. All the acids $\mathrm{H}_{2} \mathrm{SO}_{4}$ were used as received without further purification. The $\mathrm{CoSO}_{4}$ (Aldrich) and $\mathrm{PbSO}_{4}$ (Aldrich) and $\mathrm{FeSO}_{4}(\mathrm{BDH})$ were used as received. The electrolyte solutions were prepared using de-ionised water from a Millipore purification system. The carbon graphite working electrode was polished on a felt polishing cloth to obtain a glassy finish. The bentonite modified electrode was prepared as described by Orata and Segor (12). 
In generating the cyclic potential scans, two sets of instruments were used. These comprised of a Princeton Applied Research (PAR) model 173 potentiostat/galvanostat, a logarithmic current converter model 369 that controlled the current, a PAR model 175 universal programmer and a PAR RE $0089 \mathrm{X}-\mathrm{Y}$ recorder.

\section{Results and Discussion :}

\section{i).Electroanalysis on bare carbon electrode :}

This system was studied in a solution containing $1 \mathrm{M} \mathrm{H}_{2} \mathrm{SO}_{4}$ as supporting electrolyte and $500 \mathrm{mg}$ of $\mathrm{n}$ - acetyl para-aminophenol (paracetamol). The potential of the working electrode was cycled from $-0.4 \mathrm{~V}$ to $1.2 \mathrm{~V}$. The scan rate was $20 \mathrm{mV} / \mathrm{sec}$. The cyclic voltammetric response obtained showed an oxidative shoulder at $0.600 \mathrm{~V}$ and a sharp oxidative peak at $0.750 \mathrm{~V}$. This peak at $0.750 \mathrm{~V}$ is characterized by a sharp switching potential followed by a very strong Faradaic decay, with very little evidence of a double layer charging. The reduction peaks occur at $0.645 \mathrm{~V}$ and

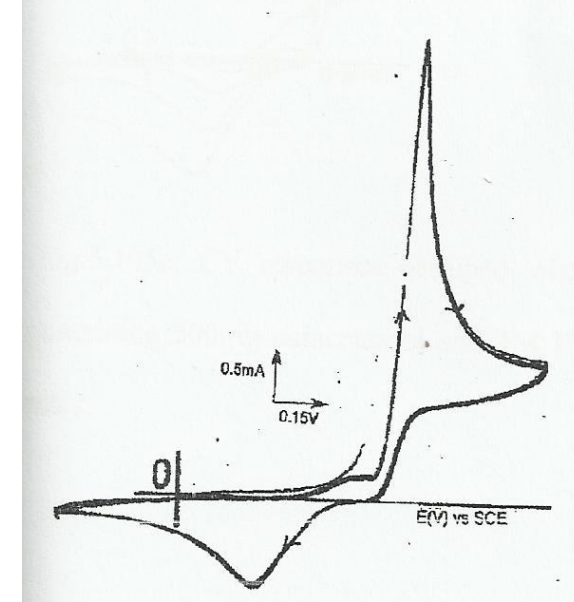

Fig. 1a: CV response obtained when bare carbon electrode was cycled in a solution containing 500mg paracetamol and $1 \mathrm{M} \mathrm{H}_{2} \mathrm{SO}_{4}$. Scan rate of $20 \mathrm{mV} / \mathrm{sec}$

$0.270 \mathrm{~V}$. The peak at $0.270 \mathrm{~V}$ is well defined (see figure 1a) and it showed significant variation with scan rate (see figure 1b).

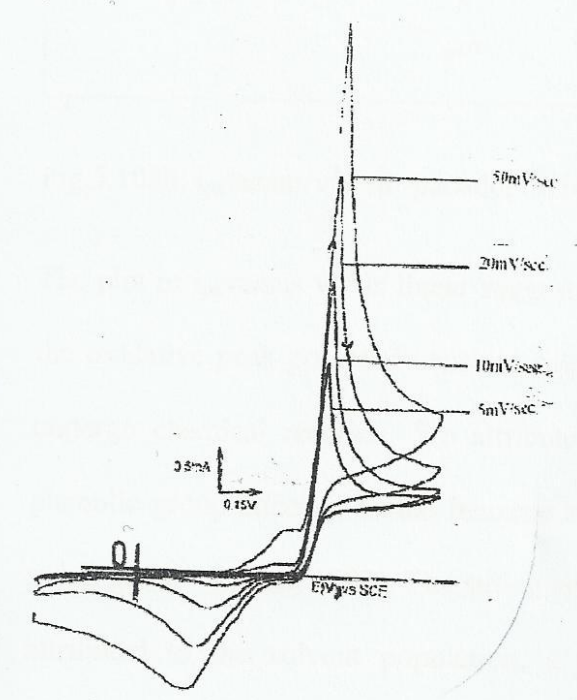

Fig.1b: Cyclic voltammograms obtained on variation of scan rate

The plot of $\mathrm{i}_{\mathrm{pa}}$ versus $\mathrm{v}^{1 / 2}$ is linear suggesting a diffusion limited process. The increase of $\mathrm{i}_{\mathrm{pa}}$ with $\mathrm{v}^{1 / 2}$ with the oxidative peak potential constant suggests that the oxidative species is stable and does not undergo chemical reaction. This is attributed to the oxidation /reduction associated with the phenolic group attached to 
the benzene ring. This type of response is characteristic of phenol redox process (13). The strong switching potential for the reduction process observed at $0.255 \mathrm{~V}$ can be attributed to the solvent population, a phenomenon observed in the conducting polymer, polyaniline where the oxidative peak current obtained during the first scan is always much higher than that of the second peak (see figure 2).
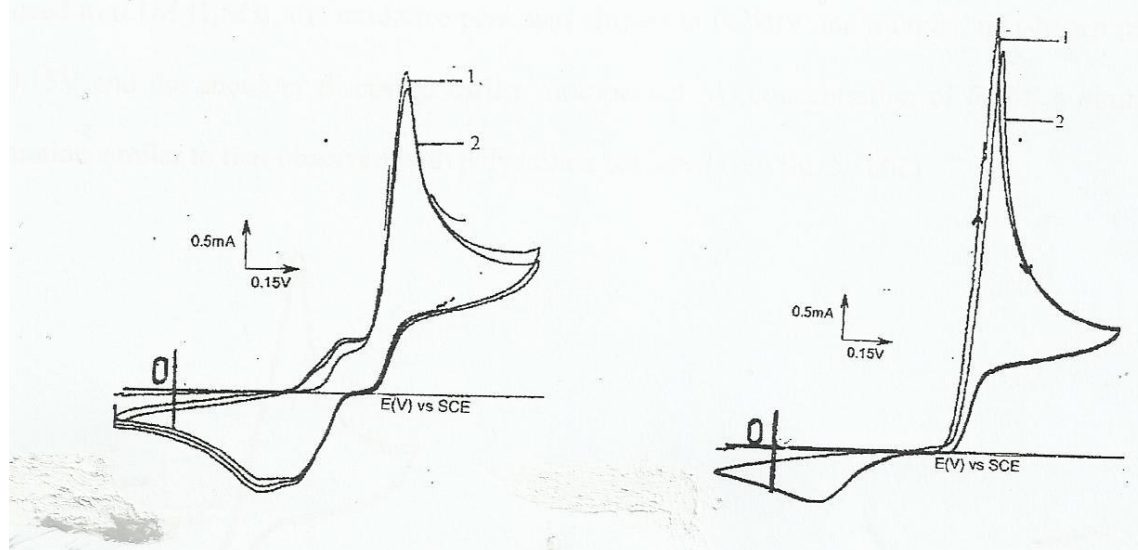

Fig2a: CV response obtained when bare carbon electrode was cycled in a solution containing $500 \mathrm{mg}$ paracetamol and $1 \mathrm{M} \mathrm{H}_{2} \mathrm{SO}_{4}$.Potential range $-0.2 \mathrm{~V}$ to $1.2 \mathrm{~V}$.

Fig 2b: CV response obtained when bare carbon electrode was cycled in a solution containing 500mg paracetamol and $0.5 \mathrm{M} \mathrm{H}_{2} \mathrm{SO}_{4}$.Potential range $-0.2 \mathrm{~V}$ to $1.2 \mathrm{~V}$.

The total charge under the reduction peak is $42.8 \%$ of that of the oxidation peak. This difference suggests that not all oxidative species are reduced. It is possible that during the oxidation we have formation of acetic acid and para-aminophenol derivatives. The latter can undergo oxidation/reduction forming radical cations which will couple in head to head fashion leading to the formation of a dimer. When the concentration of the supporting electrolyte was decreased to $0.5 \mathrm{M} \mathrm{H}_{2} \mathrm{SO}_{4}$, the oxidation peak potential decreased by about $60 \mathrm{mV}$ while the reduction peak potential reduces by $120 \mathrm{mV}$ (see figure $2 \mathrm{~b}$ ). When the concentration of the supporting electrolyte was reduced to $0.1 \mathrm{M} \mathrm{H}_{2} \mathrm{SO}_{4}$, the oxidative peak shifted to $0.780 \mathrm{~V}$ and a broad, mishapened peak occurred at $0.15 \mathrm{~V}$. The shoulder discussed earlier disappeared. In the $0.1 \mathrm{M} \mathrm{H}_{2} \mathrm{SO}_{4}$, it appears we have formation of a dimer (see figure 3 ).

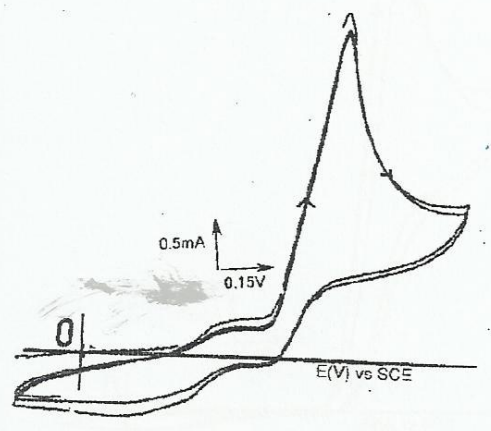

Fig.3:CV response obtained when bare carbon electrode was cycled in a solution containing 500mg paracetamol and $0.1 \mathrm{M} \mathrm{H}_{2} \mathrm{SO}_{4}$. Potential range $-0.2 \mathrm{~V}$ to $1.2 \mathrm{~V}$

As $\mathrm{pH}$ increases it appears that dimerisation is significantly reduced and the paracetamol undergoes hydrolysis to form quinone derivatives.

When similar experiments were repeated using $\mathrm{HCl}$, the oxidative peak potential is observed at $0.795 \mathrm{~V}$ with a poorly defined reduction peak (see figure 4 ). 


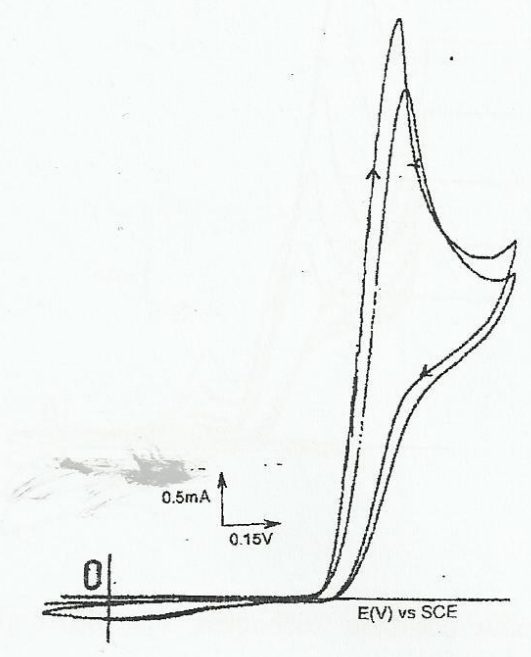

Fig 4: $\mathrm{CV}$ response obtained when bare carbon electrode was cycled in s a solution containing $500 \mathrm{mg}$ paracetamol and $1 \mathrm{M} \mathrm{HCl}$. Potential range $-0.4 \mathrm{~V}$ to $1.2 \mathrm{~V}$.

On increasing scan rate, the cyclic voltammetric response obtained at higher scan rate is the same as the one for ascorbic acid. This suggests that in $\mathrm{HCl}$, the redox process leads to the formation of para-aminophenol and acetic acid. The para-aminophenol as already shown will form radical cation which will combine in a head to head fashion. A reduction of the concentration of $\mathrm{HCl}$ yielded new oxidation/ reduction peaks at about $0.450 \mathrm{~V}$ and $0.330 \mathrm{~V}$ respectively. We propose that this reduction process is associated with the dimer which resulted from head to head coupling of the radical cations. These oxidation/reduction potentials resemble those seen in the case of polyaniline (ref) even though in this particular case we have head to tail coupling with the anilinium radical cations due to the absence of phenolic groups. The resultant structure polymerizes into a long chain in the case of polyaniline. The extensive conjugation of in the polymer lowers the oxidation potential as compared to that observed in para-aminophenol.

\section{ii).Bentonite modified working electrode:}

To enhance the paracetamol electrochemical signal we modified the working electorode surface with a slurry made of bentonite and paracetamol. The slurry was then used to dipcoat the working electrode surface. This electrode was then transferred to a solution containing $1 \mathrm{M} \mathrm{H}_{2} \mathrm{SO}_{4}$ and the potential cycled from $-0.4 \mathrm{~V}$ to $1.2 \mathrm{~V}$ at a scan rate of $20 \mathrm{mV} / \mathrm{sec}$. The cyclic voltammetric response obtained is shown in figure 5.109 . We obtained well defined oxidation peaks occurring at $0.570 \mathrm{~V}$ and $0.225 \mathrm{~V}$ respectively.

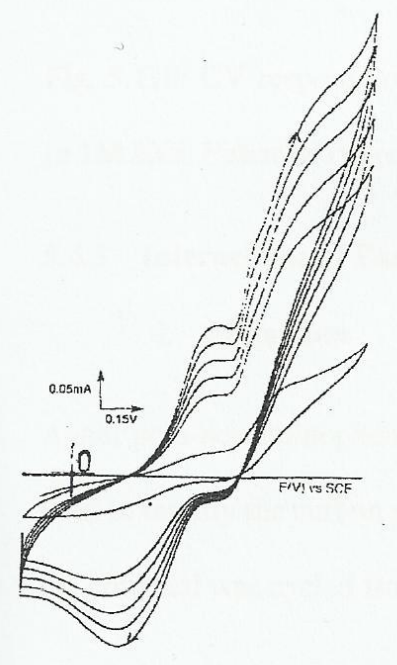

Fig. 5: CV response obtained when a bentonite-paracetamol modified electrode was cycled in $1 \mathrm{M} \mathrm{H}_{2} \mathrm{SO}_{4}$. Potential range: $-0.4 \mathrm{~V}$ to $1.2 \mathrm{~V}$. Scan rate of $20 \mathrm{mV} / \mathrm{sec}$ 
The redox peaks can be attributed to the redox activity of the dimeric material formed from head to head coupling. A repeat of the same analysis in $1 \mathrm{M} \mathrm{HCl}$ yielded the ascorbic acid type peak (see figure 6), once again suggesting formation of para-aminophenol and acetic acid.

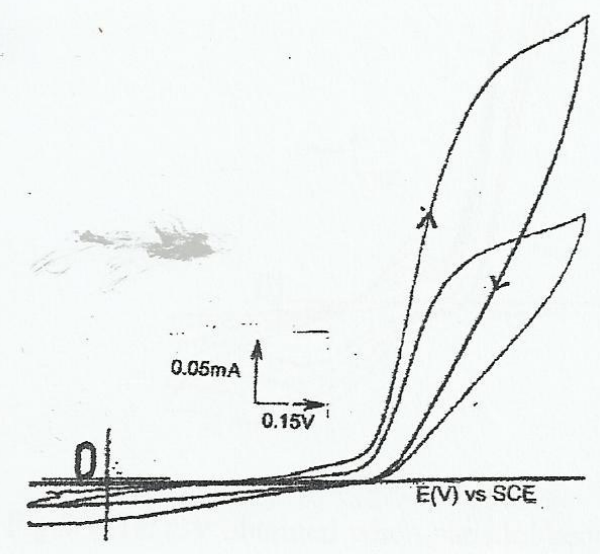

Fig.6: CV response obtained when a bentonite/paracetamol modified electrode was cycled in $1 \mathrm{M} \mathrm{HCl}$. Potential range: $-\mathbf{0 . 2 V}$ to $1.2 \mathrm{~V}$.

\section{iii).Interactions of paracetamol with metal ions:}

Again para-acetaminophenol and $\mathrm{Co}^{2+}$ were mixed together with bentonite to make a slurry, which was then used to modify the carbon graphite working electrode. The supporting electrolyte was $\mathrm{H}_{2} \mathrm{SO}_{4}$ and the potential was cycled from $-0.4 \mathrm{~V}$ to $01.2 \mathrm{~V}$ at a scan rate of $20 \mathrm{mV} / \mathrm{sec}$ (see figure $7 \mathrm{a}$ and $7 \mathrm{~b}$ ).
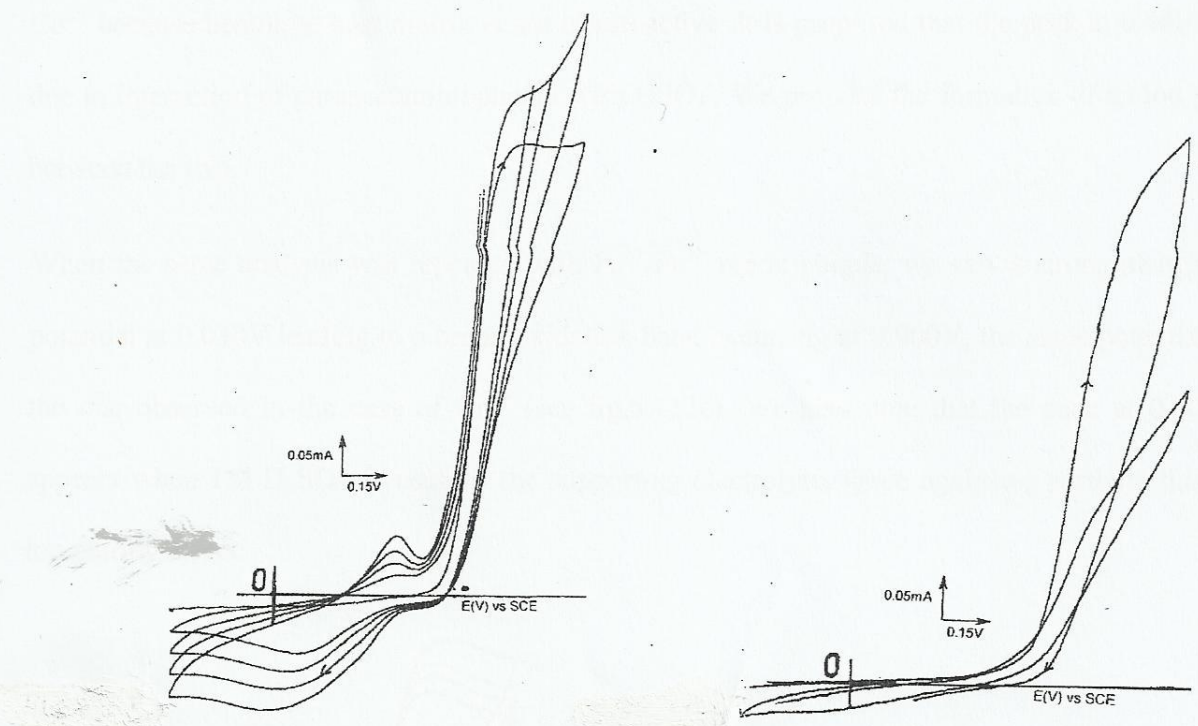

Fig. 7a: CV obtained when paracetamol/bentonite/ $\mathrm{Co}^{2+}$ modified electrode potential was cycled in $1 \mathrm{M}$ $\mathrm{H}_{2} \mathrm{SO}_{4}$. Potential range: $-0.4 \mathrm{~V}$ to $1.2 \mathrm{~V}$. Scan rate: $20 \mathrm{mV} / \mathrm{sec}$

Fig. 7b: CV obtained when panadol/bentonite/ $\mathrm{Co}^{2+}$ modified electrode was cycled in $1 \mathrm{MHCl}$. Potential range: $-0.4 \mathrm{~V}$ to $1.2 \mathrm{~V}$. Scan rate: $20 \mathrm{mV} / \mathrm{sec}$

The resultant cyclic voltammetric response is shown in figure $7 \mathrm{a}$. We observe an oxidation peak at $0.465 \mathrm{~V}$ with a broad reductive peak at approximately $0.00 \mathrm{~V}$. At the far positive potential end we observe a peak resembling that of ascorbic acid. The oxidation peak at $0.465 \mathrm{~V}$ increased with continuing cycling. In $\mathrm{HCl}$ we observe that oxidation peak at $0.465 \mathrm{~V}$ is totally suppressed (see figure $7 \mathrm{~b}$ ). The suppression of the peak at $0.465 \mathrm{~V}$ is probably attributable to the presence of chloride ions and remotely to $\left[\mathrm{H}^{+}\right]$given that $\mathrm{HCl}$ is a monoprotic acid. We observe that in the absence of $\mathrm{Co}^{2+}$ and bentonite the cyclic voltammogram obtained exhibited a very distinct switching potential at $0.600 \mathrm{~V}$ and a well defined peak at $0.480 \mathrm{~V}$. It is apparent that the peak observed at $0.480 \mathrm{~V}$ can be attributed to the $\mathrm{Co}^{2+}$ because bentonite host matrix is not electroactive. It is 
proposed that the peak at $0.465 \mathrm{~V}$ is due to interaction of paraacetaminophenol with $\mathrm{HSO}_{4}{ }^{-}$. We propose the formation of an ion pair between the two.

When the same analysis was repeated with $\mathrm{Fe}^{2+} / \mathrm{Fe}^{3+}$ redox couple, there was a strong switching potential at $0.030 \mathrm{~V}$ leading to a broad oxidation band occurring at $0.900 \mathrm{~V}$, the same potential as the one observed in the case of $\mathrm{Co}^{2+}$ (see figure 5.111c). It was also noted that the peak at $0.300 \mathrm{~V}$ appeared when $1 \mathrm{M}$ $\mathrm{H}_{2} \mathrm{SO} 4$ was used as the supporting electrolyte. Once again this can be attributed to the ion pairing effect.

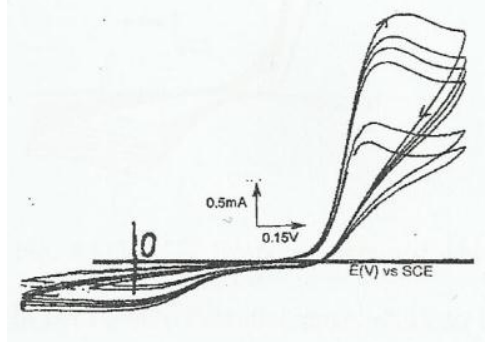

Fig. 7c: CV Response for paracetamol/bentonite/ $\mathrm{Fe}^{2+} / \mathrm{Fe}^{3+}$ modified electrode in $1 \mathrm{M}$ $\mathrm{H}_{2} \mathrm{SO}_{4}$. Potential range: $-\mathbf{0 . 4 \mathrm { V }}$ to $1.2 \mathrm{~V}$. Scan rate: $20 \mathrm{mV} / \mathrm{sec}$

The two metal ions $\mathrm{Co}^{2+}$ and $\mathrm{Fe}^{2+}$ do not seem to interfere at all with the paracetamol redox peaks suggesting that, their redox centres are independent.

\section{b). Interactions of paracetamol with consummables:}

Since paracetamol is an analgesic used extensively by patients, its interaction with common consumables/beverages tea and milk was studied. We obtain well defined redox peaks are obtained as shown in figure 8 , with a strong switching potential at $0.630 \mathrm{~V}$.

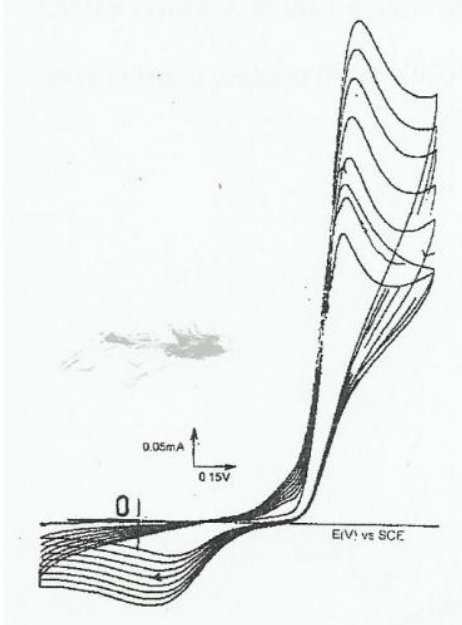

Fig.8: CV response obtained when paracetamol/bentonite/tea modified electrode was cycled in $1 \mathrm{M}_{2} \mathrm{SO}_{4}$. Potential range: $-\mathbf{0 . 4 V}$ to $1.2 \mathrm{~V}$.

In the case of tea the oxidation potential occurred at $0.855 \mathrm{~V}$ which is $75 \mathrm{mV}$ more positive than was the case for $\mathrm{Co}^{2+}$ and $\mathrm{Fe}^{2+}$. The increase in the oxidative potential can be attributed to the phenolic groups in tea. It is not surprising that the electrochemical signal is significantly enhanced given that the redox spheres of the phenolic groups in paracetamol and phenolic groups can interact albeit in a complementary manner. In the presence of tea, the oxidation peak previously observed at $0.465 \mathrm{~V}$ disappears even though a broad reduction peak is observed at $0.00 \mathrm{~V}$. The disappearance of the oxidative peak can be attributed to interference of the phenolic groups in tea with the ion pairs formed between para-acetaminophenol and $\mathrm{HSO}_{4}{ }^{-}$ions.

On the contrary, in the presence of milk, a peak was observed at $0.465 \mathrm{~V}$. A broad reduction and oxidation peaks is further observed at $0 \mathrm{~V}$ at $0.900 \mathrm{~V}$ respectively (see figure $9 \mathrm{a}$ ). 

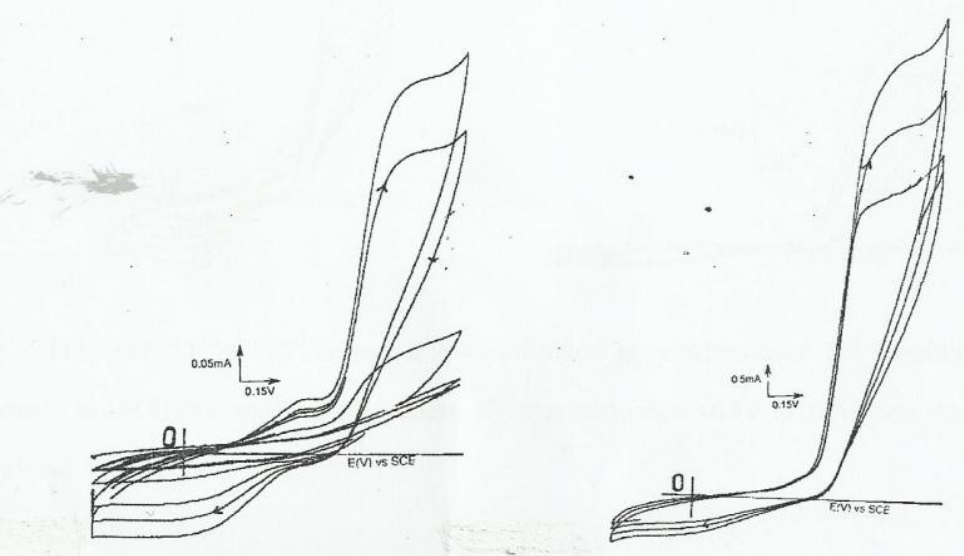

Fig.9a and 9b: CV responses obtained when paracetamol/bentonite/milk modified electrode was cycled in $1 \mathrm{M} \mathrm{H} \mathrm{HO}_{4}$ and $1 \mathrm{M} \mathrm{HCl}$ respectively. Potential range: $-0.4 \mathrm{~V}$ to $1.2 \mathrm{~V}$.

In the presence of $\mathrm{HCl}$ (see figure $9 \mathrm{~b}$ ), the oxidation peak at $0.465 \mathrm{~V}$ and the broad reduction peak at $0.00 \mathrm{~V}$ were not observed. This is not the case for $\mathrm{H}_{2} \mathrm{SO}_{4}$ and can be attributed once again to the formation of ions pair in the presence of $\mathrm{H}_{2} \mathrm{SO}_{4}$ (see figure 9a).

The influence of $\mathrm{Pb}^{2+}$ on the redox activity of para-acetaminophenol in bentonite was also studied. The resultant cyclic voltammograms are shown in figures $10 \mathrm{a}$ and $10 \mathrm{~b}$ for $1 \mathrm{M} \mathrm{H}_{2} \mathrm{SO}_{4}$ and $1 \mathrm{M} \mathrm{HCl}$ electrolyte media respectively.

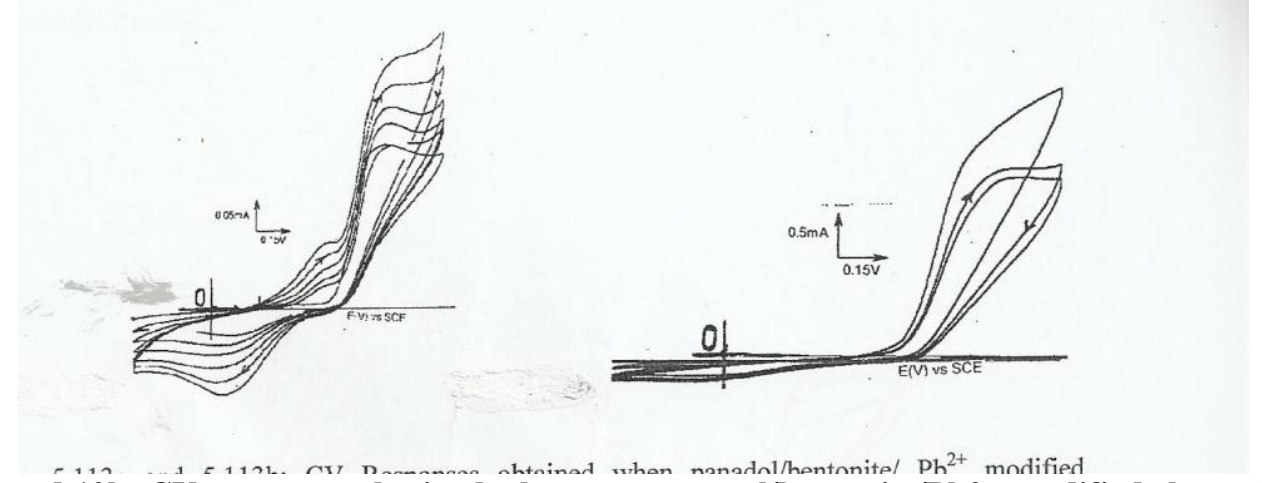

Figs.10a and 10b: CV responses obtained when paracetamol/bentonite/Pb2+ modified electrode in $1 \mathrm{M}$ $\mathrm{H}_{2} \mathrm{SO}_{4}$ and $1 \mathrm{M} \mathrm{HCl}$ respectively. Potential range: $-0.4 \mathrm{~V}$ to $1.2 \mathrm{~V}$.

It is observed that the peak which was attributed to ion pair at $0.465 \mathrm{~V}$ now appears at $0.435 \mathrm{~V}$. We also observe an oxidation peak at $0.900 \mathrm{~V}$ and a reduction peak at $0.15 \mathrm{~V}$. In the case of $\mathrm{HCl}$ supporting electrolyte, we observe complete inhibition of redox peak observed at $0.600 \mathrm{~V}$ and $0.15 \mathrm{~V}$. This once again suggests ion pairing effect between $\mathrm{HSO}_{4}{ }^{-}$and para-acetaminophenol in $1 \mathrm{M} \mathrm{H}_{2} \mathrm{SO}_{4}$ media. The $\mathrm{Pb}^{2+}$ interacts with the ion pair formed between $\mathrm{HSO}_{4}{ }^{-} / \mathrm{SO}_{4}{ }^{2-}$ and para-acetaminophenol leading to entropic stabilization of the system, hence a decrease in the oxidative potential.

When similar experiments were repeated using ferrous fumerate (a birth control pill) we observe that in both $\mathrm{HCl}$ and $\mathrm{H}_{2} \mathrm{SO}_{4}$ electrolyte media (see figure $11 \mathrm{a}$ and figure $11 \mathrm{~b}$ ), the peak at $0.465 \mathrm{~V}$ is absent. We also observe that the oxidative peak potential for the para-acetaminophenol now appears at $0.825 \mathrm{~V}$ in both electrolyte media. 


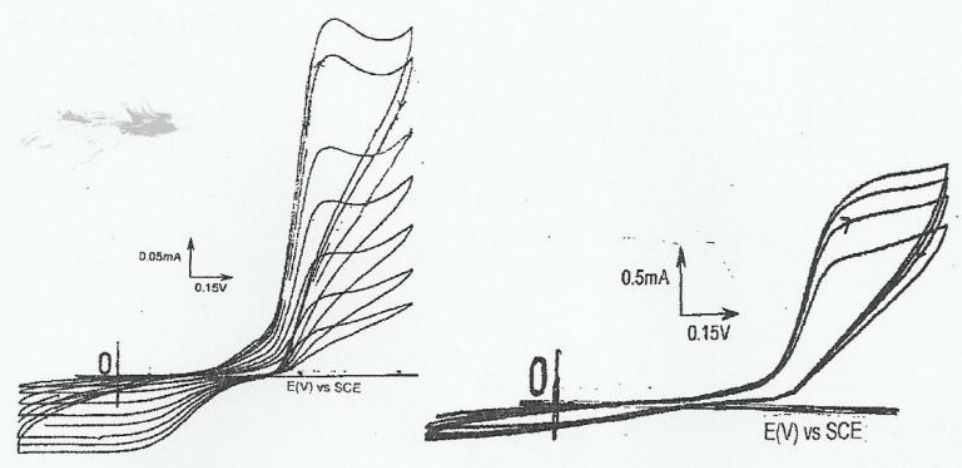

Figs. 11a and 11b: CV responses obtained when paracetamol/bentonite/ferrous fumarate modified electrode was cycled in $1 \mathrm{M} \mathrm{H}_{2} \mathrm{SO}_{4}$ and $1 \mathrm{M} \mathrm{HCl}$ respectively. Potential range: $-\mathbf{0 . 4 \mathrm { V }}$ to $1.2 \mathrm{~V}$.

Based on the observations, the birth control pill does not affect the redox properties of paraacetaminophenol. This observation is noteworthy, in that, at the electrochemical level paracetamol and ferrous fumarate appear not to interefere with each other. It thus, possible that at the physiological level in living beings the status quo is maintained. This assertion is purely speculative.

When the electrode surface was modified with folic-acid/bentonite/para-acetaminophenol, the cyclic voltammograms obtained in $\mathrm{HCl}$ and $\mathrm{H}_{2} \mathrm{SO}_{4}$ electrolyte media were quite distinct (see figures $12 \mathrm{a}$ and $12 \mathrm{~b}$ ).

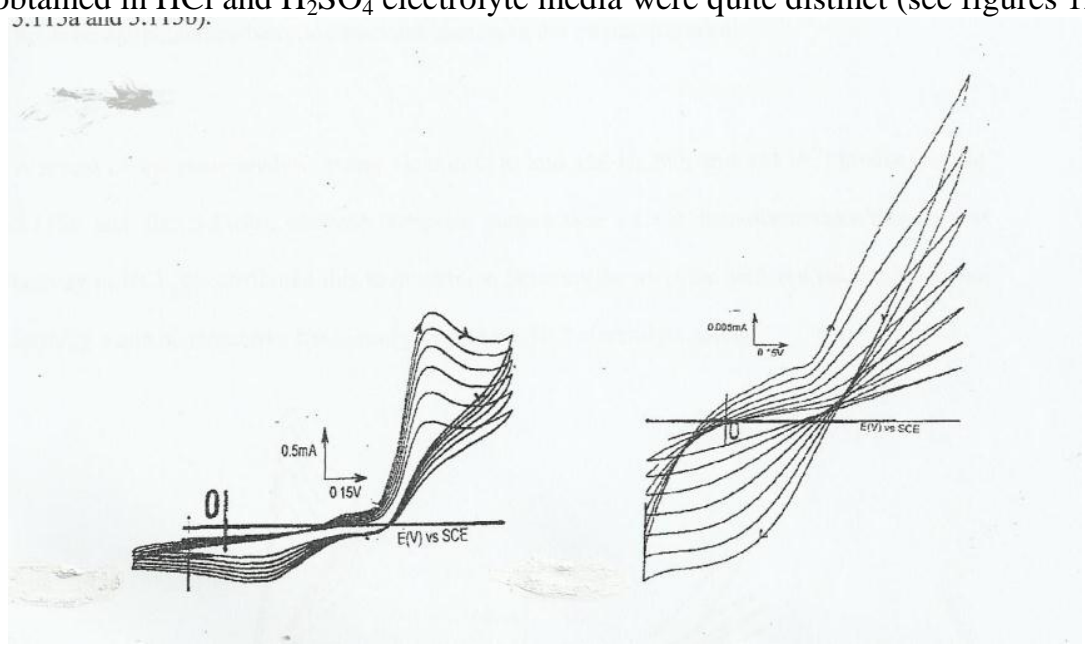

Fig. 12a: CV response obtained when paracetamol/bentonite/ folic acid modified electrode was cycled in $1 \mathrm{M} \mathrm{H}_{2} \mathrm{SO}_{4}$. Potential range: $-0.4 \mathrm{~V}$ to $1.2 \mathrm{~V}$. Scan rate: $20 \mathrm{mV} / \mathrm{sec}$

Fig. 12b: CV response obtained when paracetamol/bentonite/ folic acid modified electrode was cycled in $1 \mathrm{M} \mathrm{HCl}$ respectively. Potential range: $-0.4 \mathrm{~V}$ to $1.2 \mathrm{~V}$. Scan rate: $20 \mathrm{mV} / \mathrm{sec}$

In the $\mathrm{HCl}$ media, the redox activity of para-acetaminophenol is completely suppressed depicting poor electron transfer kinetics. This suggests a chemical reaction between folic acid and para-acetaminophenol leading to the formation of electron inactive species. This is not the case in $\mathrm{H}_{2} \mathrm{SO}_{4}$ where we obtained a well defined shoulder at $0.480 \mathrm{~V}$ and a distinct oxidative peak at $0.825 \mathrm{~V}$. A broad reduction peak is observed at approximately $0.090 \mathrm{~V}$. We observe that the redox activity attributed earlier on to ion pairing effect was significantly reduced while the redox activity of para-acetaminophenol was enhanced. It is possible that the enhanced peak observed at $0.825 \mathrm{~V}$ is the result of the redox activity of amide redox moieties resulting from interaction between amino and carboxylic functional groups in the interacting species.

A repeat of the same analysis using vitamin $\mathrm{C}$ in and $1 \mathrm{M} \mathrm{H}_{2} \mathrm{SO}_{4}$ and $1 \mathrm{M} \mathrm{HCl}$ media (see figures $13 \mathrm{a}$ and $13 \mathrm{~b}$ ), showed complete suppression of the para-acetaminophenol redox activity in $\mathrm{HCl}$. We attributed this to interaction between the ascorbic acid and para-aminophenol forming a non electroactive species in the $\mathrm{HCl}$ electrolyte media. 

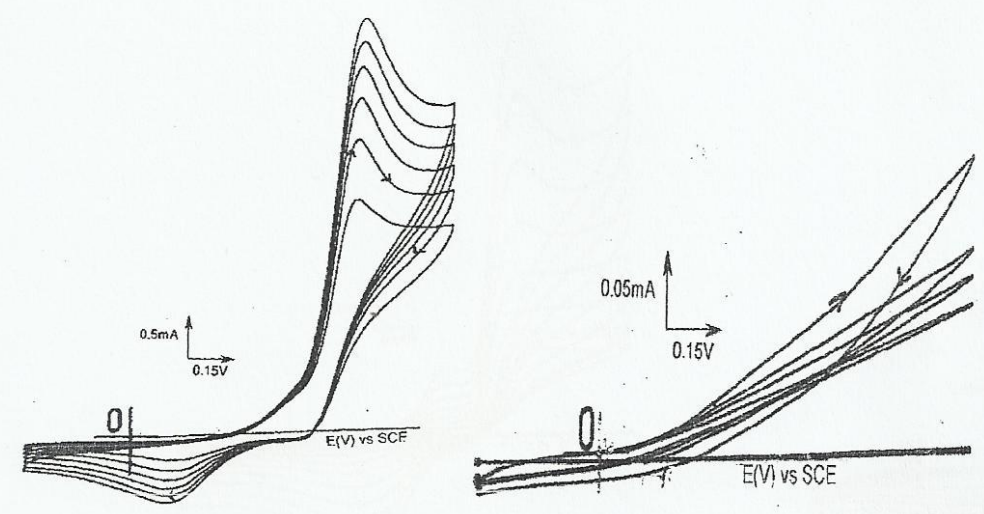

Figs. 13a and 13b: CV responses obtained when paracetamol/bentonite/vitamin modified electrode was cycled in $1 \mathrm{M} \mathrm{H}_{2} \mathrm{SO}_{4}$ and $\mathrm{HCl}$ respectively. Potential range: $-0.4 \mathrm{~V}$ to $1.2 \mathrm{~V}$. Scan rate: $20 \mathrm{mV} / \mathrm{sec}$

In the case of $\mathrm{H}_{2} \mathrm{SO}_{4}$, we observe a well defined oxidation peak at $0.825 \mathrm{~V}$ and a reduction peak at $0.150 \mathrm{~V}$. The amide bond is formed leads to enhanced redox activity. The electroinactivity associated with the $\mathrm{HCl}$ electrolyte media is probably the result of ingress of the high charge density $\mathrm{Cl}^{-}$into the basal layer of the clay montmorillonite hence reducing/or curtailing its interaction with paraacetaminophenol. In the case of $\mathrm{H}_{2}$ $\mathrm{SO}_{4}$ electrolytic media, the anions $\mathrm{HSO}_{4}{ }^{-}$and $\mathrm{SO}_{4}{ }^{2-}$ have low charge density due to their sizes; hence the rate of their incorporation into the basal layer of the clay montmorillonite is significantly reduced. Therefore, the paraacetaminophenol has reasonable contact time with the anions hence the enhanced redox activity.

In another set of experiments, hydrocortisone was incorporated in the slurry for use in electrode modification. The cyclic voltammetric response for hydrocortisone/bentonite/para-acetaminophenol working electrode is shown in figures $14 \mathrm{a}$ and $14 \mathrm{~b}$.

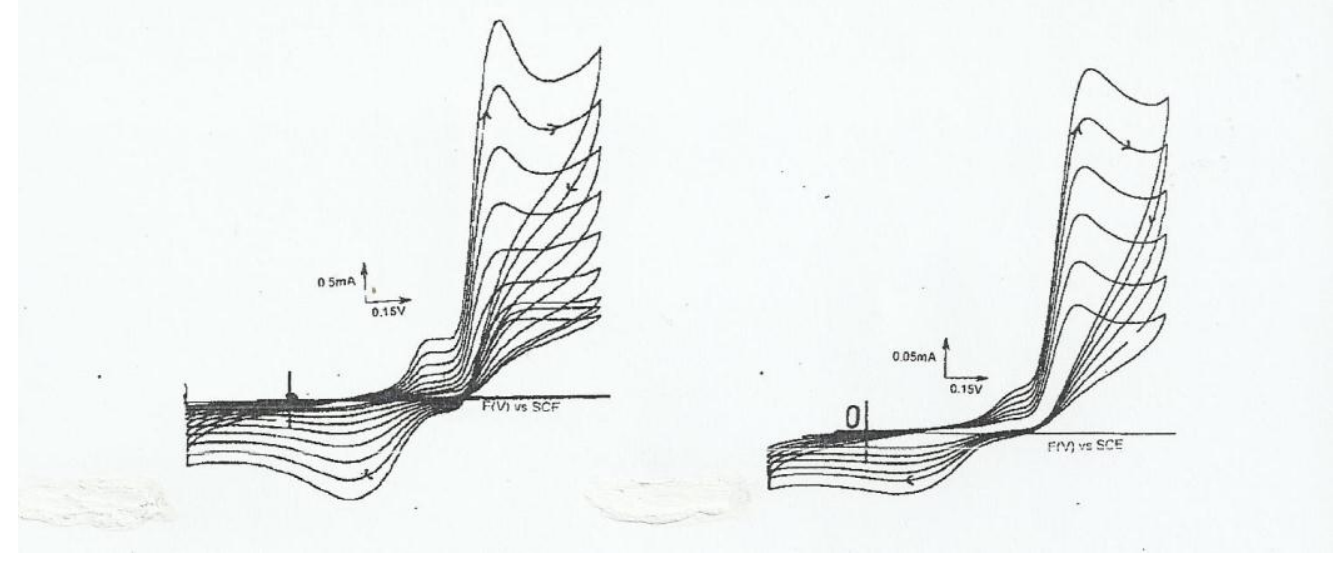

Figs. 14a and 14b: CV responses obtained when paracetamol/bentonite/hydrocortisone modified electrode was cycled in $1 \mathrm{M} \mathrm{H}_{2} \mathrm{SO}_{4}$ and $\mathrm{HCl}$ respectively. Potential range: $-0.4 \mathrm{~V}$ to $1.2 \mathrm{~V}$. Scan rate: $20 \mathrm{mV} / \mathrm{sec}$

Unlike in the case of folic acid and ascorbic acid, the redox activity of the para-acetaminophenol was not suppressed. This suggests that, the hydrocortisone which is a corticosteroid does not inhibit or react with the para-acetaminophenol to produce an electroinactive species. Due to the stability of the corticosteroid chemical structure, it does not react chemically with the para-acetaminophenol. The corticosteroid sterically hinders the ingress of $\mathrm{Cl}^{-}$into the bentonite hence allowing contact between para-acetaminophenol and $\mathrm{Cl}^{-}$hence, the observed redox activity in $\mathrm{HCl}$.

\section{Conclusion:}

Paracemol is a very important analgesic/pain killer used extensively across the board by most patients. Thus the observations regarding its interaction with metal ions, $\mathrm{Co}^{2+}, \mathrm{Pb}^{2+}$, milk, tea, ferrous fumarate, vitamin $\mathrm{C}$, folic acid and hydrocortisone at the electrochemical level, if replicated at the biochemical level can give a lot of insight on its mode of action and interactions subsequently its administration as a prescription drug. 


\section{References:}

[1]. Scottish Intercollegiate Guidelines Network (SIGN) (2008). Guideline 106: Control of pain in adults with cancer. Scotland: National Health Service

[2]. Khashab M., Tector A.J., Kwo P.Y. (2007). "Epidemiology of acute liver failure". Curr Gastroenterol Rep 9 (1): 66-73

[3]. Hawkins L.C., Edwards J.N., Dargan P.I. (2007). "Impact of restricting paracetamol pack sizes on paracetamol poisoning in the United Kingdom: a review of the literature". Drug Saf 30 (6): 465-79.

[4]. Larson A.M., Polson J., and Fontana R.J. (2005). "Acetaminophen-induced acute liver failure: results of a United States multicenter, prospective study". Hepatology 42 (6): 1364-72

[5]. Hinz, B., Cheremina O. and Brune K. (2008). "Acetaminophen (paracetamol) is a selective cyclooxygenase-2 inhibitor in man.". The FASEB journal : official publication of the Federation of American Societies for Experimental Biology 22 (2): 383-390

[6]. Bertolini A., Ferrari A., Ottani A., Guerzoni S., Tacchi R. and Leone S. (2006). "Paracetamol: new vistas of an old drug". CNS Drug Reviews 12 (3-4): 250-75.

[7]. Aronoff D.M., Oates J.A. and Boutaud O. (2006). "New insights into the mechanism of action of acetaminophen: Its clinical pharmacologic characteristics reflect its inhibition of the two prostaglandin H2 synthases". Clin. Pharmacol. Ther. 79 (1): 9-19.

Kis B., Snipes J.A. and Busija D.W. (2005). "Acetaminophen and the cyclooxygenase-3 puzzle: sorting out facts, fictions, and uncertainties". J. Pharmacol. Exp. Ther. 315 (1): 1-7.

[8]. Graham G.G. and Scott K.F. (2005). "Mechanism of action of paracetamol". American journal of therapeutics 12 (1): $46-55$

[9]. Ellis, F. (2002). Paracetamol: a curriculum resource. Cambridge: Royal Society of Chemistry.

[10]. Anthony S. T. (2007). "Manufacture and uses of the anilines: A vast array of processes and products". In Zvi Rappoport. The chemistry of Anilines Part 1. Wiley. p. 764

[11]. Elmar F., Thomas C. and Helmut B. (2005), "Analgesics and Antipyretics", Ullmann's Encyclopedia of Industrial Chemistry, Weinheim: Wiley-VCH.

[12]. Orata, D.O and Segor F. (1999), Bentonite as a template for electro- synthesis of thyroxine Catalysis letter 58, $157-163$.

[13]. Orata D. O., (1992), Electrochemical characteristics of polyaniline electropolymerized on a 